\title{
NEVE PARA REFRESCAR: REFLEXÕES SOBRE RELATIVIDADE LINGUÍSTICA CONDICIONADA PELO AMBIENTE NO ESTUDO CIENTÍFICO DAS LÍNGUAS HUMANAS
}

\author{
SNOW FOR COOLING DOWN: REFLECTIONS ON LINGUISTIC RELATIVITY \\ CONDITIONED BY THE ENVIRONMENT IN THE SCIENTIFIC STUDY \\ OF HUMAN LANGUAGES
}

\author{
Marco Antonio Esteves da Rocha | Lattes | marcor@cce.ufsc.br \\ João Paulo Zarelli Rocha | Lattes |jpzarelli@gmail.com \\ Universidade Federal de Santa Catarina
}

Resumo: Este trabalho pretende, através de uma análise da controvérsia a respeito da quantidade de palavras existentes em esquimó para referir-se a neve, fazer uma reflexão sobre as noções de palavra, significado e relatividade linguística, conforme definidas na hipótese Sapir-Whorf, e em relação com a lexicografia. Após explorar os primórdios da controvérsia com base nas formulações de Franz Boas no final do séc. XIX, o exemplo é utilizado para investigar o possível efeito que a estrutura gramatical e o léxico de uma língua podem ter sobre a maneira como os falantes desta língua percebem o mundo, já que estes aspectos do conhecimento linguístico seriam condicionados pelo meio ambiente no qual os falantes desta língua vivem. As contestações frequentemente sarcásticas sobre a associação entre estes aspectos da hipótese Sapir-Whorf e a quantidade de palavras para referir-se a neve em esquimó são discutidas, com uso intensivo de material relacionado a parâmetros bem estabelecidos da tipologia linguística. Elementos novos revelados por pesquisas recentes são incorporados à análise do condicionamento cultural e ambiental da semântica lexical das línguas. Estas investigações atuais parecem na verdade corroborar as conclusões iniciais de Boas quanto à grande variedade de palavras para referir-se a neve em esquimó, em termos de distinções significativas, tanto morfológicas quanto semânticas. A discussão conclui com uma ênfase na importância do conhecimento humano expresso por estas distinções, a despeito dos usos de tais informações em contextos não especializados, como palestras "inspiradoras" para profissionais de vendas, as quais seriam potencialmente equivocadas em termos de padrões científicos de estudo das línguas.

Palavras-chave: Língua esquimó; Relatividade linguística; Semântica lexical; Tipologia linguística. 
Abstract: The present work reflects on the notions of word, meaning and linguistic relativity, as presented in the Sapir-Whorf hypothesis, and in relation with lexicography by analysing the controversy regarding the amount of words in Eskimo for snow. After exploring the early days of the controversy based on the remarks of Franz Boas in the end of the 19th century, the example is utilized for investigating the possible effect that the grammatical structure and the lexicon of a language may have over the way speakers of this language perceive the world, since these aspects of the linguistic knowledge would be conditioned by where the speakers of this language live. The frequently sarcastic arguments that associate these aspects of the Sapir-Whorf hypothesis and the amount of words for snow are discussed with intensive use of material related to well-established parameters of the linguistic typology. New elements revealed by recent research are incorporated into the analysis of cultural and environmental conditioning of lexical semantics of languages. These current investigations seem to support Boas's initial conclusions regarding the wide variety of words for snow in Eskimo, in terms of both morphological and semantics significant distinctions. The discussion concludes by emphasising the importance of human knowledge expressed by these distinctions, despite the uses of this information in non-specialized contexts, such as "motivational" speeches for sales professionals, which would be potentially misguided in terms of scientific standards of language studies.

Keywords: Eskimo language; Linguistic relativity; Lexical semantics; Linguistic typology.

\footnotetext{
"I shall give you a composition, shall I? I have not prepared one, so it will have to be something from my memory. Listen, but do not try to count my words. Don't even think about counting. Just listen."

Bee Ridgway, The River of No Return
}

\section{Introdução}

A controvérsia em torno do número de palavras existentes na língua dos esquimós para designar neve tomou proporções consideravelmente exageradas, se levarmos em conta os graves problemas metodológicos intrínsecos à ideia de contar palavras com uma dada referência no mundo real. A discussão relevante está associada à noção, convencionalmente chamada de relatividade linguística, que postula um condicionamento cultural e ambiental de uma determinada língua, através da qual o próprio modo de pensar dos falantes nativos também seria por sua vez condicionado.

O antropólogo Franz Boas foi o iniciador, muito provavelmente involuntário, do debate que, hoje em dia, já se estende por mais de um século. Suas viagens pela ilha de 
Baffin, no norte do Canadá durante os anos 1880, pretendiam apenas ser um meio de estudar a vida das populações esquimós locais através de uma pesquisa de campo, participando diretamente das suas viagens de trenó e do comércio de peles, e obtendo, no processo, informações também sobre o folclore. Orgulhoso do êxito da sua integração ao modo de vida dos esquimós, Boas (1998), em carta para sua noiva, contou que havia se tornado "[...] truly like an Eskimo [...] living entirely on seal meat." Manifestava também o quanto estava intrigado com a língua dos esquimós, fazendo observações sobre a ampla variedade da terminologia utilizada para descrever a paisagem gelada. Para citar apenas dois destes termos, Boas (1998) menciona aquilokoq para neve macia que cai e piegnartoq para neve [que é] boa para passar de trenó.

Ao incluir estas observações na introdução de seu livro, o Handbook of American Indian Languages, Boas (1911), que também tinha formação de linguista, deflagrou o processo de disseminação da crença que apregoa que os esquimós têm dezenas e, em algumas versões, até mesmo centenas de palavras para neve. A ideia continua a atrair a imaginação do público em geral, mas muitos linguistas consideram a afirmação um mito, criado pelo exagero jornalístico e pela pesquisa superficial dos que não são especialistas da área - em suma, aquilo que é geralmente denominado, com algum menosprezo, de ciência popular. As críticas destes especialistas são resumidamente apresentadas e analisadas em seguida.

\section{$2 \mathrm{O}$ esquimó no âmbito da tipologia linguística}

O esquimó é a principal língua da família esquimó-aleuta. As línguas que compõem o nome da família, esquimó e aleuta, são as duas únicas que fazem parte desta família. Segundo informações contidas no Languages of the World, de Katzner (1977), o esquimó é falado por aproximadamente 100.000 pessoas na Groenlândia, no Canadá, no Alaska e na Sibéria. O aleuta é falado por aproximadamente 2.300 pessoas nas ilhas Aleutas (hoje em dia parte dos EUA), mais cerca de 150 pessoas nas ilhas Commander, parte da Rússia (KRAUSS, 2007, p. 408). Não há dúvida, aplicando os princípios do método histórico-comparativo (FOWLER, 1957), quanto à existência de um parentesco entre essas duas línguas, que podem, consequentemente, ser agrupadas em uma família. ${ }^{2}$ Isto significa que houve, algum dia, um proto-esquimó-aleuta, ainda que não haja

\footnotetext{
1 “[...] realmente um esquimó, [...] se alimentando exclusivamente de carne de foca." Reproduzido, em tradução dos autores para o português, conforme citado no artigo de Robson (2012).

2 Para uma breve introdução sobre estudos histórico-comparativos, ver Gonçalves e Basso (2010). Para uma discussão profunda não só sobre linguística comparativa e linguística histórica, mas também sobre variação, mudança e tipologia linguística, ver Matasović (2009).
} 
dados sobre esta antiga língua (HIRSCH, 1954). Há, não obstante, pesquisas fidedignas relacionadas à reconstrução do idioma, como Bergsland (1986), Fortescue (1998) e Woodbury (2017), que foram especialmente possibilitadas pelos trabalhos de Marsh e Swadesh (1951) até Fortescue, Jacobson e Kaplan (1994).

Hoje em dia, porém, estas duas línguas são muito diferentes, o que indica que começaram a se afastar há mais de mil anos. Uhlenbeck (1906) acreditava inclusive que o aleuta não podia ser enquadrado junto do esquimó na mesma família. No ano seguinte, $o$ autor refuta a própria afirmação, mas ainda define que o esquimó ocidental e o esquimó oriental têm mais proximidade do que o esquimó ocidental e o aleuta (UHLENBECK, 1907). Muitas tentativas foram feitas para vincular o esquimó a outras famílias de línguas indígenas da América do Norte, como também da Sibéria (chukchi), da Ásia Central e até a subfamílias indo-europeias (VOORT, 2008). Pesquisas relevantes foram desenvolvidas nestas tentativas, mas não parece haver fundamento científico suficiente para inclusão do esquimó e do aleuta em nenhuma outra família de línguas. É mais prudente manter a família de apenas duas línguas à parte. Vale destacar também que a palavra esquimó não pertence ao léxico da língua esquimó. Tem origem na língua Cree, dos índios também chamados de Cree, vizinhos próximos na área da baía de Hudson. Katzner (1977, p. 253) e Barsness (2002, p. 75) afirmam que esquimó significa comedores de carne crua, o que é taxado por Brightman (2007, p. 157) como uma narrativa estereotipada provinda do próprio Cristoforo Colombo, e Cutler (2000, p. 198) afirma que é apenas uma palavra homônima à uma raça de cães da Sibéria. Os esquimós chamam a si mesmos de inuit, palavra que significa povo (ou gente, pessoas) (KATZNER, 1977, p. 253). O termo é frequentemente usado no Canadá e, atualmente, também por órgãos oficiais, em demonstração de respeito. Às vezes aparece como referência à língua, mas o termo mais adequado para o idioma é inuktitut.

Embora esparsamente povoado, o território pelo qual se espalham os falantes de esquimó é vastíssimo. Não obstante, a variação dialetal existente pode ser definida por um agrupamento de dois dialetos principais, o inupik (às vezes inuit) e o yupik, os quais são mutuamente ininteligíveis (KATZNER, 1977, p. 253). Ambos contêm uma variedade de subdialetos. Sem dúvida é possível que alguns destes subdialetos contenham mais palavras relacionadas a neve e gelo que algum outro dialeto, mas a questão que parece ser mais importante seria o grau de urbanização da população que utiliza uma determinada variante, já que o cotidiano de uso da língua nas regiões menos urbanizadas exigiria maiores nuances na definição das características da neve e do gelo no ambiente. Isso nos leva 
à questão central da discussão: como contar as palavras, isto é, com base em que critérios seria possível concluir que uma dada palavra é uma das que se refere à neve, permitindo então, após um levantamento completo, que as palavras definidas como referentes à neve fossem contadas. É frutífero lembrar que não é possível realizar um mapeamento de correspondências simples entre palavras e objetos pré-existentes no mundo. A palavra elemento, por exemplo, tem conotações bastante distintas quando usada no contexto do discurso científico da Química, em comparação ao contexto da crônica policial.

No caso do esquimó, a noção de palavra, já em si problemática, é particularmente difícil. O esquimó é uma língua polissintética típica, frequentemente mencionada em trabalhos relacionados à tipologia linguística. Segundo essa tipologia, existem três grandes tipos de língua humana: as línguas analíticas; as línguas sintéticas; e as línguas polissintéticas (PRIA, 2006). As línguas analíticas, como o chinês, tendem a apresentar uma correspondência simples entre palavra e significado. ${ }^{3}$ Deste modo, māo (猫) significa gato, e xiăo (小) significa pequeno. A palavra gatinho teria como correspondente xiăomāo (小猫). A forma plural gatinhos teria a mesma forma, xiăomāo, sem nenhuma marca de flexão de plural, e o mesmo se aplica às formas femininas gatinha e gatinhas. Não há flexão de gênero e número, exceto nos pronomes, que possuem formas flexionadas de plural. As línguas nunca são totalmente analíticas ou totalmente sintéticas, ou ainda totalmente polissintéticas, ainda que seja possível classificá-las com base nestes tipos por conta da predominância de uma forma de correspondência entre palavra e significado.

O esquimó situa-se no outro extremo do espectro tipológico. Orações inteiras podem ser expressas por uma única palavra, através do acréscimo de uma série de afixos de significados gramaticais complexos. O português se situa entre o chinês (língua tipicamente analítica) e o esquimó (língua tipicamente polissintética). É uma língua apenas sintética, mas não polissintética. As palavras podem conter flexões, mas, na enorme maioria dos casos, não podem ser orações. Abaixo está um exemplo de oração em esquimó (1), extraído de Eifring e Theil (2005), seguido de uma tradução para a língua portuguesa (2), feita pelos autores com base na glosa em inglês do original. Esta, por sua vez, é seguida por uma retextualização correspondente em chinês (3) e uma glosa em português:

(1) Utaqqiguvinga, aullaqatiginiaqpagit. esperar se 2PSg 1PSg, ir parceiro ter futuro assertiva $2 \mathrm{PSg} / 1 \mathrm{PSg}$

\footnotetext{
${ }^{3} \mathrm{O}$ mandarim é comumente confundido com o chinês; porém, o primeiro é considerado uma variante da língua chinesa. Variante, aliás, que não se limita somente ao dialeto de Beijing (SHEN, 2011).
} 
(2) Se você me esperar, eu vou (irei) com você.

(3) Nĭ děng wŏ, wŏ jiù gēn nĭ qù. (你等我, 我就跟你去。)

Você esperar eu, eu então com você ir.

$\mathrm{O}$ texto em chinês não contém nenhuma flexão. $\mathrm{O}$ pronome de primeira pessoa wŏ aparece como objeto na primeira oração, mas como sujeito na segunda oração, sem que haja qualquer flexão ou modificação da forma. As formas verbais também não apresentam flexão. Os verbos chineses têm apenas uma forma para todos os modos, tempos e pessoas (WALLS; WALLS, 2009, p. 6). Mesmo a conjunção se pode ser dispensada como marca de subordinada condicional, ainda que o jiù da segunda oração acabe servindo como marca de consequência imediata, com uma função semelhante. Os verbos do português são flexionados de maneira a sinalizar modo, tempo e pessoa. Ainda que seja possível encontrar variações destas orações com significado semelhante, estas estruturas são normalmente aceitas em cada uma das línguas.

A retextualização em esquimó contém apenas duas palavras, que são, na verdade, correspondentes a duas orações. Tanto a primeira quanto a segunda têm início com uma forma verbal seguida de uma série de morfemas flexionais de natureza gramatical. Deste modo, o início da palavra utaqqiguvinga é utaqqi e significa esperar, o sufixo gu marca o condicional (se), seguido por $v i$, que assinala a segunda pessoa do singular (2PSg), e finalmente por $n g a$, a marca de primeira pessoa. A ordem de aparecimento permite a identificação de vi como sujeito e de nga como objeto. É importante ressaltar que nenhum destes morfemas constituem palavras independentes.

O processo é um tanto mais complexo na palavra aullaqatiginiaqpagit. Também neste caso o morfema inicial aulla é a forma verbal e significa ir. Seguem-se qati (parceiro); gi (ter); niaq, morfema que marca o tempo futuro; $p a$, partícula que assinala que está sendo feita uma afirmação; e, por fim, git, um morfema que une primeira e segunda pessoa, marcando a ação em conjunto (EIFRING; THEIL, 2005). Tendo em vista este tipo de processo de formação de termos, a própria ideia de palavra torna-se bastante distinta da que tipicamente corresponde à língua portuguesa. Em consequência desta característica das línguas polissintéticas, contar as palavras que se referem a neve ou gelo em esquimó pode ser uma tarefa bastante complexa, o que seguramente influenciou em boa medida o surgimento e a subsequente evolução desproporcional da controvérsia. 
O processo baseado em formas verbais apresentado acima também ocorre com substantivos, em alguns casos permitindo que a verve descritiva do falante possa se expressar de maneira relativamente incomum. Um lexicógrafo que pretenda compilar um dicionário do esquimó, portanto, está diante de uma tarefa particularmente difícil, uma vez que é preciso decidir se o termo angyagh, uma variação de kayak (barco) no dialeto yupik centro-siberiano, será incluído apenas uma única vez como um radical, deixando de lado "palavras" como angyaghllangyugtuqlu, isto é, "ainda por cima, ele quer um barco maior”. Percebe-se, assim, que o dicionário poderia facilmente fugir do controle do lexicógrafo empenhado na tarefa de construir um dicionário do esquimó, dado que a identificação das palavras que precisam ser incluídas no dicionário é uma questão linguística complexa.

\section{0 posicionamento da linguística acadêmica}

Franz Boas era alemão, da cidade de Minden. Suas excursões como antropólogo ao Ártico resultaram em sua emigração definitiva para a América do Norte, mais especificamente para os Estados Unidos, onde tornou-se professor de antropologia da Universidade de Columbia a partir de 1899. Suas ideias quanto à interação entre antropologia e linguística influenciaram um outro linguista-antropólogo alemão de Lauenburg (atualmente a cidade faz parte da Polônia), Edward Sapir. Sapir também emigrou para os Estados Unidos e tornou-se aluno da Universidade de Columbia, onde se aprofundou nas ideias de interação entre língua e cultura já delineadas por Boas. Mais tarde, acabou definindo conclusões quanto ao efeito que a estrutura gramatical e o léxico de uma língua podem ter sobre a maneira como os seus falantes percebem o mundo. Essas conclusões foram desenvolvidas por seu aluno, Benjamin Lee Whorf, e acabaram por ser conhecidas como a hipótese Sapir-Whorf, associada a fenômenos como a profusão de termos para neve e gelo em esquimó. ${ }^{4}$

Os termos para neve e gelo do esquimó acabaram sendo adotados como exemplo de capacidade de adaptação, ou ainda de qualquer outra coisa que um palestrante pago queira demonstrar, através de "conteúdos" linguísticos, em uma reunião de vendedores preocupados com as dificuldades de sobrevivência em um mercado hostil. Isto em si não implica erro, do ponto de vista da ciência das línguas humanas, mas é comum que os linguistas reajam desfavoravelmente a este tipo de uso superficial e potencialmente leviano de material linguístico. Durante a crise financeira de 2008, por exemplo, passou a ser

\footnotetext{
${ }^{4}$ Porções de informações sobre Sapir e Whorf retiradas de entradas escritas pelos editores da Encyclopcedia Britannica, de 2003 e 2009 respectivamente, e da contribuição de Tax (2007) sobre Boas para a mesma referência.
} 
frequente, em palestras "inspiradoras" do tipo mencionado acima, declarar que a "palavra crise em chinês contém o ideograma oportunidade". A citação talvez tenha um efeito bom para o moral dos que enfrentam dificuldades no mercado, mas, do ponto de vista linguístico, é altamente questionável, já que “a palavra crise” em foco (危机 [wéijī]) é composta por dois caracteres chineses (os linguistas também não gostam do termo ideograma): 危, que significa perigo; e 机, que significa momento e também máquina (um celular, por exemplo, é um shŏujī (手机), literalmente, máquina de mão). Trata-se, portanto, de um momento de perigo. Esse processo de formação de palavras é comum em chinês, já que, desconsideradas exceções menores, não há morfemas derivacionais.

Expressões em língua portuguesa como aproveitar o momento indicam que a palavra momento também pode significar oportunidade em português. Em consequência, a sabedoria chinesa não acrescenta grande coisa ao nosso entendimento de uma crise. Não é, estrito senso, verdade que os chineses, filosoficamente, vejam em uma crise um momento de oportunidade. Apenas utilizam um processo de formação de palavras comum na língua. Não obstante, há falantes nativos do chinês que defendem a noção de dualidade taoista intrínseca às palavras chinesas (yin e yang), da qual crise seria um exemplo lapidar, posição que é no mínimo questionável. A palavra geralmente usada para oportunidade é, no entanto, jīhui (机会). O segundo caractere significa momento oportuno, o que cria uma palavra com dois caracteres reiterativos, formação de palavras também comum em chinês. São estas muitas nuances do conhecimento linguístico humano que geram controvérsias prolongadas, uma vez que o entendimento real da natureza deste conhecimento ainda é incipiente.

O fato é que, não importa por que razões obscuras, o esquimó passou a ser o cavalo de batalha preferido dos linguistas para caracterizar o mau uso do conhecimento das línguas humanas em palestras do tipo acima mencionado. Um marco de destaque dessa reação é o livro de Pullum (1991), The Great Eskimo Vocabulary Hoax and Other Irreverent Essays on the Study of Language. O ensaio, segundo o autor, não é sobre lexicografia esquimó, mas sobre indolência intelectual, conforme detectada em palestras ligadas à psicologia da administração e à solução de problemas gerenciais. A argumentação no texto cita inicialmente o Dictionary of the West Greenlandic Eskimo Language, de Schultz-Lorentzen (1927), no qual estão incluídos apenas dois radicais relacionados à neve: qanik, que significa "neve no ar" ou "floco de neve"; e aput, que significa "neve no solo".

\footnotetext{
${ }^{5}$ A declaração vira moda por ter sido utilizada por John Kennedy em 1959 na United Negro College Fund e por Lisa no décimo primeiro episódio da sexta temporada de The Simpsons, reproduzido pela primeira vez em 1994 na Fox.
} 
Em seguida, o autor descreve os resultados de sua consulta ao "melhor esquimologista” de suas relações, o professor Anthony Woodbury, da Universidade do Texas em Austin. A questão da necessidade de especificar um dos dialetos do esquimó é mencionada primeiro; em seguida, é destacada a presença de um alto grau de fenômenos polissintéticos na morfologia do esquimó. O professor Woodbury (1991) chama a atenção para a existência de por volta de 280 morfemas flexionais para cada radical nominal na língua em questão. Decidir o que é uma palavra "diferente" para neve pode ser bastante difícil. Mesmo em morfologias bem mais simples, como a do português, é fácil perceber que existem decisões a serem tomadas. Tanto neve quanto nevasca são duas palavras que se referem à neve? A raiz é a mesma, mas os significados não são os mesmos. Qual critério prevalece? O morfológico sugere uma inclusão de nevasca no verbete neve em um dicionário. O semântico sugere uma "palavra" diferente para referir-se a uma situação específica que abrange neve.

Outro aspecto do problema é a existência de termos equivocadamente incluídos nas listas de palavras para neve em esquimó, segundo Woodbury (1991). O termo igluk$s a k$, por exemplo, foi incluído em uma lista de vinte termos para neve em esquimó enviada por Edith Moravcsik, da Universidade de Wisconsin, para Pullum. Woodbury assinala que o termo é formado por iglu, que significa casa, e o afixo - ksak, que significa material para. O termo foi incluído na lista com o significado de neve para fazer iglu, mas na verdade quer dizer simplesmente material para construir casas. Não se trata, em absoluto, de um tipo especial de neve, de acordo com o autor. Poderia referir-se à madeira, pregos, tijolos ou telhas. $\mathrm{O}$ fato de que estes materiais podem ser muito raros em alguns dos ambientes habitados por esquimós, fazendo com que o uso real do termo tenha de fato, como referência do mundo real, neve, não é determinante para o significado, segundo as explicações de Woodbury reproduzidas por Pullum.

Após a publicação do livro de Pullum (1991), Woodbury (1991) recebeu muitos pedidos de jornalistas em busca de esclarecimentos mais completos sobre a questão. Ainda em 1991, Woodbury publica então um artigo intitulado Counting Eskimo Words for Snow: A Citizen's Guide. No artigo, é apresentada uma lista de lexemas - isto é, itens lexicais independentes, grosso modo equivalentes a verbetes distintos de dicionário - que se referem a neve no dialeto yupik do Alaska Central. A lista contém quinze lexemas, organizados segundo o significado e agrupados em quatro grandes classes. Woodbury deixa por conta do leitor a decisão de "contar" estes quinze lexemas como quinze palavras para se referir a neve, mas chama a atenção para problemas intrínsecos à contagem, a saber: 
(a) Os quinze lexemas de fato se referem a neve, ou seja, significam neve?

(b) Sinônimos, caso existam, contam como duas palavras para neve?

(c) Verbos e substantivos com o mesmo significado contam como duas palavras? Nos dicionários, de um modo geral, constituem dois verbetes separados.

(d) Concentrar-se em um único dialeto resolve a questão da variação dialetal? Termos distintos em função de variação dialetal contam como duas palavras?

A lista de Woodbury (1991) é reproduzida abaixo traduzida para o português. Os símbolos NUN (nunivak), NS (subdialeto do estreito de Norton), NSU (estreito de Norton, subdialeto unaliq), Y (subdialeto da área do rio Yukon) e HBC (baía de Hooper e Chevak) referem-se a variações dialetais. Os hifens no final de palavras sinalizam que outros morfemas são habitualmente acrescentados aos lexemas apresentados, isto é, que estas formas, de um modo geral, não ocorrem em isolamento. Os quatro grandes grupos semânticos são utilizados para organizar o material da mesma forma que foi feito por Woodbury, apenas com as denominações traduzidas para o português:

A. Partículas de neve

(1) Floco de neve

qanuk - floco de neve

qanir- - nevar

qanunge- - nevar [NUN]

qanugglir- - nevar [NUN]

(2) Geada/gelo

kaneq - geada; gelo

kaner- - estar gelado; gelar alguma coisa

(3) Partículas finas de neve/chuva

kanevvluk - partículas finas de neve/gelo

kanevcir- - ter partículas finas de neve/gelo

(4) Partículas levadas pelo vento natquik - neve levada pelo vento natqu(v)igte- - neve levada pelo vento junto ao solo

(5) Partículas grudadas nevluk - detritos/neve/poeira... etc. grudada nevlugte- - ter detritos/neve/poeira... etc. grudada 
B. Neve no solo

(6) Neve que caiu no solo aniu [NS] - neve no solo aniu- $[\mathrm{NS}]$ - ter neve no solo apun $[\mathrm{NS}]$ - neve no solo qanikcaq - neve no solo qanikcir- - ter neve no solo

(7) neve fofa e alta que caiu no solo muruaneq - neve macia e alta

(8) Crosta sobre neve que caiu qetrar- $[\mathrm{NSU}]$ - formar crosta em neve qerretrar- $[\mathrm{NSU}]$ - formar crosta em neve

(9) Neve que caiu recentemente no solo nutaryuk - neve recente (fresca) [HBC]

(10) Neve que caiu flutuando na água qanisqineq - neve que caiu flutuando na água

C. Formações de neve

(11) Barranco de neve qengaruk - barranco de neve [Y, HBC]

(12) Bloco de neve utvak - neve talhada em bloco

(13) Neve pendente navcaq $[\mathrm{NSU}]$ - neve pendente, (formação de) neve prestes a cair navcite- - ser pego por uma avalanche

D. Eventos meteorológicos

(14) Tempestade de neve, nevasca pirta - tempestade de neve, nevasca pircir- - ocorrer uma nevasca, tempestade de neve pirtuk - tempestade de neve, nevasca

(15) Nevasca forte cellallir-, cellarrlir- - nevar forte $\operatorname{pir}(\mathrm{e}) \mathrm{t}(\mathrm{e})$ pag- - nevar forte pirrelvag- - nevar forte

Um exame dos argumentos até aqui apresentados não parece justificar o sarcasmo e o menosprezo, expressos no artigo de Pullum (1991) já a partir do título, pela ideia 
de uma variedade de formas para fazer referência a neve em esquimó. $\mathrm{O}$ argumento em Schultz-Lorentzen (1927), da maneira que foi levantado, simplesmente não é válido, uma vez que não há detalhamento algum sobre a metodologia de compilação - houve coleta de dados diretamente com os falantes nativos? -, nem sobre as dimensões do dicionário e as condições em que sua publicação ocorreu. Além disso, as duas palavras em questão distinguem, em termos simplificados, neve no ar de neve no solo, o que já demonstra a incorporação de informações ambientais ao léxico de uma forma que não seria pensada por um habitante do Crato, no Ceará, para quem certamente não haveria motivo para pensar em duas neves diferentes por conta do contato com o solo.

\section{A reação dos defensores da relatividade linguística}

As questões relacionadas à variação dialetal e à natureza polissintética do esquimó são sem dúvida relevantes, mas também não parecem justificar tanto deboche, nem o descarte sumário da noção de variedade lexical como consequência de uma determinada cultura, a qual decorre, pelo menos em parte, das condições ambientais. Além disso, Pullum (1991) parece ter selecionado as informações, transmitidas em comunicação pessoal por Woodbury (1991), que seriam mais úteis para as suas intenções, já que a lista no artigo subsequente de Woodbury na verdade corrobora a variedade lexical apontada na hipótese Sapir-Whorf, pois contém palavras para neve pendente, neve recente, neve flutuando na água e neve que tem crosta, cada uma destas em um lexema diferente. É fácil perceber o quanto referências deste tipo seriam improváveis na língua de populações que não convivem com a neve.

Também não é difícil perceber que, certamente, há mais de duas palavras para fazer referência a neve, e que as questões dialetais e morfológicas podem seguramente justificar moderação na contagem, mas não alteram, em nenhum sentido fundamental, a proposta de interpretação da variedade lexical em função de condicionamento cultural. Pullum (1991) argumenta que a língua inglesa tem tantas palavras para neve quanto o esquimó, se consideradas apenas os lexemas distintos. Os lexemas mais frequentes para se referir a neve em inglês, segundo Durham (2015, p. 176), são: snow (neve); hail (granizo); sleet (saraiva, isto é, neve com chuva) ice (gelo), icicle (pingente de gelo), slush (neve parcialmente derretida), e snowflake (floco de neve).

Além destas, a palavra relacionada glacier (geleira) pode ser incluída na lista, ainda que mais rara, como também os termos de esqui pack, powder, crud e crust. A própria inclusão destes termos poderia ser questionada, como também a inclusão de snowflake. 
O mais importante, porém, é a conclusão, agora inevitável, que contar palavras não é uma opção metodológica ponderada. Nation e Waring (2000) compartilham dessa conclusão, ao realizar um levantamento sobre o histórico das listas de frequência - wordlists, na nomenclatura para softwares de linguística de corpus - e afirmam ainda que, analogamente, é inútil questionar quantas palavras um aprendiz de uma língua deve conhecer para determinar se há conhecimento naquela língua. A avaliação da relatividade linguística, no sentido do condicionamento cultural e ambiental, dos termos para neve do esquimó parece suficientemente clara, a despeito dos possíveis usos indevidos e palestras que procuram ser interessantes através de exemplos linguísticos questionáveis.

Uma vez que o esquimó é a língua que gera a confrontação mais ferrenha, os defensores da relatividade linguística dispõem de uma grande quantidade de exemplos, em muitas outras línguas do mundo, e podem, sem dificuldade, lançar mão de uma variedade de características menos polêmicas presentes no léxico destas línguas. A língua fulani, também conhecida como fula ou fulbe, é falada por aproximadamente quinze milhões de pessoas em uma ampla faixa da África Ocidental. Por volta de oito milhões destes falantes estão concentrados no norte da Nigéria, enquanto os demais sete milhões se espalham por Guiné, Guiné-Bissau, Senegal, Gâmbia, Mauritânia, Mali, Burkina Faso, Níger e Camarões (NJEUMA, 2012).

Mukoshy (2014) registra 82 palavras para gado, dentre elas: guddiri (touro sem cauda); wudde (vaca sem cauda); jaabuye (vaca com umbigo grande); lelwaaye (gado com olhos de gazela); haapuye (vaca com leite depois que seu bezerro morreu); gerlaaye (vaca que parece ave selvagem); mbutuye (vaca cujo bezerro morreu e pode ir para a engorda). Os termos servem a propósitos do cotidiano. Ainda em Mukoshy (2014), há uma outra variedade de termos relacionados aos chifres: elliinge (gado com chifres para cima); gajje (gado com os chifres virados para trás); hippe (gado com os chifres pendentes para a frente); hogole (gado com chifres que quase se tocam); lettooye (gado com um chifre para cima e o outro pendente); wijaaye (gado com chifres pendentes na direção das orelhas); tolle (gado com um único chifre); wumale (gado sem chifres). A importância da criação de gado para as sociedades em questão é amplamente reconhecida, mas os falantes de fulani que moram em cidades não têm o mesmo domínio deste tipo de vocabulário, se comparados aos habitantes de áreas rurais.

Outras situações semelhantes incluem, por exemplo, as oito palavras para primo em chinês, separando primos por parte de pai de primos por parte de mãe, além de primas mulheres de primos homens e primos mais velhos de primos mais novos (as distinções são importantes; em algumas sociedades que falam chinês, os primos por parte de mãe 
podem se casar, dado que seus nomes de família não são os mesmos; porém, qualquer relação sexual entre primos paternos seria considerada incestuosa, uma vez que os nomes de família são os mesmos). Há também as 180 palavras para neve e gelo em sami, língua urálica relacionada ao finlandês e ao estoniano, falada no norte da Noruega, da Suécia, da Finlândia e no extremo noroeste da Rússia, além das centenas de palavras nesta mesma língua para rena, com distinções sutilíssimas baseadas em características físicas, personalidade e forma das galhadas (MAGGA, 2006, p. 33). Vale destacar que o sami não é uma língua polissintética, o que torna a identificação de palavras muito mais fácil (EIFRING; THEIL, 2005).

Todavia, é o esquimó que fascina linguistas e antropólogos, assim como o grande público que consome a chamada ciência popular em periódicos que publicam artigos dessa natureza. Mais recentemente, portanto, Krupnik (apud ROBSON, 2012), antropólogo do Centro Smithsoniano de Estudos Árticos, em Washington, mapeou, juntamente com sua equipe, o léxico de cerca de dez dialetos de inupik e yupik, tomando o cuidado de considerar apenas formas que representassem "distinções significativas", e concluiu que, de fato, estas populações têm muito mais palavras para neve do que o inglês (KRUPNIK et al., 2010). O yupik da Sibéria Central tem quarenta termos para neve, e no dialeto inuit da região de Nunavik, no Canadá, haveria 53 termos para neve, tais como matsaaruti, para neve molhada que pode ser usada para untar os patins de um trenó, e pukak, para neve cristalina em pó que parece sal.

Em vários destes dialetos, o vocabulário relacionado a gelo no mar é ainda mais rico. Krupnik et al. (2010) registraram, no dialeto inupiaq, do Alaska, mais de 70 termos para gelo, os quais definem distinções tais como utuqaq, gelo que dura ano após ano; siguliaksrak, a camada de pedaços de cristais de gelo que se forma quando o mar começa a congelar; e auniq, gelo com muitos buracos. O geofísico Matthew Sturm (apud ROBSON, 2012), que trabalha no Alaska para o Corpo de Engenharia do Exército dos EUA, afirma que o conhecimento que estas palavras representam é muito mais importante do que a picuinha quanto à contagem das palavras. O linguista Willem de Reuse (apud ROBSON, 2012) destaca que "These people need to know whether ice is fit to walk on or whether you will sink through it." ${ }^{6}$ Documentar este conhecimento seria, portanto, muito mais importante do que especificar o número de palavras existentes para neve. Segundo Krupnik et al. (2010), Boas registrou apenas uma pequena parte das palavras existentes, justamente o contrário do que pensam seus críticos.

\footnotetext{
${ }^{6}$ Estas pessoas precisam saber se o gelo está suficientemente firme para que possam caminhar sobre ele, ou se, ao contrário, afundariam se o fizessem.
} 
Em relação aos termos genéricos como o relacionado ao material de construção (igluksak), também existe contestação das críticas a Boas por parte de seus defensores. De fato, o termo refere-se a qualquer material de construção para casas, mas, no momento em que se constrói um iglu, o termo aplica-se exatamente à neve que é rígida, mas, ao mesmo tempo, suficientemente maleável para erigir uma casa semiesférica feita com blocos de neve. Portanto, diferentemente do que afirmam os críticos, trata-se realmente de um tipo específico de neve. Da mesma maneira, o termo maujaq pode ser usado para neve na qual uma pessoa afunda. Trata-se de um termo genérico que se aplica a qualquer terreno fofo, como lama, mangue ou areia movediça. Porém, no inverno destas regiões, refere-se apenas à neve fofa em que o pé afunda. A informação, perceptivelmente, pode ser muito importante para a sobrevivência.

\section{Conclusão}

O Apêndice A de SIKU: Knowing Your Ice (2010) lista 93 palavras para a terminologia do gelo no mar em Inuktitut, incluindo termos genéricos, como siku, parte do título, mas também termos altamente especializados, como qautsaulittuq, gelo que quebra quando testado com um arpão, e iniruvik, gelo que se partiu por causa de mudanças de maré, mas que voltou a congelar por causa das temperaturas baixas. Temos então uma variação entre dois termos e 93 termos, passando por doze ou quinze, o que torna o problema um tanto espinhoso, mas sem dúvida ainda muito atraente. Para os interessados em relatividade linguística, pode ser útil desenvolver uma capacidade de decidir por uma dada interpretação, diante da variedade de pontos de vista, com base em uma análise tão científica quanto possível. A atitude de deboche, representada, por exemplo, pela lista de James (2005) que circula na Internet, contendo palavras como mactla (nevebúrguer) e tlanip (neve vendida a turistas japoneses) pode ser divertida, mas não é científica.

Espera-se ter contribuído através deste trabalho para um melhor entendimento de noções como palavra, significado e relatividade linguística no contexto em questão.

\section{Referências}

BARSNESS, J. Inuit. Field \& Stream, v. 107, n. 2, p. 72-77, jun. 2002.

BERGSLAND, K. Comparative Eskimo-Aleut phonology and lexicon. Journal de la Société finno-ougrienne, v. 80, p. 63-137, 1986.

BOAS, F. Handbook of American-Indian languages. Richmond: University of California Press, 1911. 
BOAS, F.; MÜLLER-WILLE, L. Franz Boas among the Inuit of Baffin Island, 18831884: journals and letters. Edited, introduced and transcribed by Ludger Müller-Wille. Translated by William Barr. Toronto: University of Toronto Press, 1998.

BRIGHTMAN, R. A. Ācaðōhkīwina and Ācimōwina: Traditional Narratives of the Rock Cree Indians. Regina: University of Regina Press, 2007.

CUTLER, C. L. O Brave New Words! Native American Loanwords in Current English. Norman: University of Oklahoma Press, 2000.

DURHAM, R. B. Modern folklore. Raleigh: Lulu, 2015.

EIFRING, H.; THEIL, R. Linguistic Typology. In: . Linguistics for Students of Asian and African Languages. 2005. Disponível em: http://www.uio.no/studier/emner/ hf/ikos/EXFAC03-AAS/h05/larestoff/linguistics/Chapter\%204.(H05).pdf. Acesso em: 19 abr. 2015.

FORTESCUE, M.; JACOBSON, S.; KAPLAN, L. Comparative Eskimo dictionary with Aleut cognates. Fairbanks: Alaska Native Language Center, University of Alaska, 1994.

FORTESCUE, M. Language Relations across Bering Strait: Reappraising the Archaeological and Linguistic Evidence. London / New York: Cassell, 1998.

FOWLER, M. The Historical-Comparative Method. The Classical Journal, v. 52, n. 6, p. 259-264, mar. 1957.

GONÇALVES, R. T.; BASSO, R. M. História da língua. Florianópolis: LLV/CCE/UFSC, 2010.

HIRSCH, D. I. Glottochronology and Eskimo and Eskimo-Aleut Prehistory. American Anthropologist, v. 56, n. 5, p. 825-838, 1954.

JAMES, P. The Eskimos' Hundred Words for Snow. 2005. Disponível em: http://www. mendosa.com/snow.html. Acesso em: 6 dez. 2016.

KATZNER, K. The languages of the world. London: Routledge \& Kegan Paul, 1977.

KRAUSS, M. E. Native languages of Alaska. In: MIYAOKO, O.; KRAUSS, M. E. (Org.). The Vanishing Voices of the Pacific Rim. Oxford: Oxford University Press, 2007.

KRUPNIK, I. et al. (Ed.). SIKU: Knowing our ice. Washington: Springer Science and Business Media B. V., 2010.

MAGGA, O. H. Diversity in Saami terminology for reindeer, snow, and ice. International Social Science Journal, v. 58, n. 187, p. 25-34, mar. 2006.

MARSH, G.; SWADESH, M. Kleinschmidt CentennialV: Eskimo Aleut correspondences. International Journal of American Linguistics, v. 17, n. 4, p. 209-216, 1951.

MATASOVIĆ, R. Comparative and Historical Linguistics. In: SUJOLDZIC, Anita (Ed.). Linguistic Anthropology. Paris: EOLSS Publications, 2009.

MUKOSHY, I. A. A Fulfulde-English Dictionary. HEBN Publishers: Ibadan, 2014. 
NATION, P.; WARING, R. Vocabulary size, text coverage and word lists. In: SCHMITT, N.; MCCARTHY, M. (Ed.). Vocabulary: Description, Acquisition and Pedagogy. Cambridge: Cambridge University Press, 1997. p. 6-19.

NJEUMA, M. Z. Fulani Hegemony in Yola (Old Adamawa) 1809-1902. Oxford: African Books Collective, 2012.

PRIA, A. D. Tipologia lingüística: línguas analíticas e línguas sintéticas. SOLETRAS, ano VI, n. 11, p. 113-121, 2006.

PULLUM, G. K. The Great Eskimo vocabulary hoax and other irreverent essays on the study of Language. Chicago: University of Chicago Press, 1991.

ROBSON, D. Are there really 50 Eskimo words for snow? New Scientist, n. 2896, p. 72-73, 2012.

SCHULTZ-LORENTZEN, C. W. Dictionary of the West Greenlandic Eskimo Language. Copenhagen: Reitzels, 1927.

SHEN, Z. (沈钟伟) The origin of Mandarin. Journal of Chinese Linguistics, v. 39, n. 2, p. 1-31, 2011.

TAX, S. Franz Boas German-American anthropologist. Encyclopcedia Britannica, 1 dez. 2007. Disponível em: https://global.britannica.com/biography/Franz-Boas. Acesso em: 3 dez. 2016.

UHLENBECK, C. C. Zur Eskimogrammatik. Zeitschrift der Deutschen Morgenländischen Gesellschaft, v. 60, p.112-114, 1906.

. Ontwerp van eene vergelijkende vormleer der Eskimotalen. Verhandelingen der Koninklijke Akademie van Wetenschappen, Amsterdam, Johannes Müller, Afdeeling Letterkunde, v. 8, n. 3, 1907.

VOORT, H. van der. The contribution of C.C. Uhlenbeck to Eskimo-Aleut linguistics. Études / Inuit / Studies, v. 32, n. 2, p. 85-105, 2008. (Edição dedicada a Franz Boas, com editor convidado Ludger Müller-Wille).

WALLS, Y. L.; WALLS, J. Using Chinese: a guide to contemporary usage. Cambridge: Cambridge University Press, 2009.

WOODBURY, A. C. Central Alaskan Yupik (Eskimo-Aleut): A sketch of morphologically orthodox polysynthesis. In: FORTESCUE, Michael; MITHUN, Marianne; EVANS, Nicholas (Ed.). The Oxford Handbook of Polysynthesis. Oxford: Oxford University Press, 2017. Press, 1991.

Counting Eskimo words for snow: A citizen's guide. Austin: University of Texas

Submetido em: 03/03/2017

Aceito em: 31/03/2017 